\title{
Cultura e arte em tempo-de-mutação. Apocalipse ou gênese?
}

\begin{abstract}
Resumo
Este artigo discorre sobre as linhas do pensamento pós-moderno e seus reflexos na Cultura, bem como sobre o lugar que o novo homem ocupa neste tempo de transformação. Com a publicação do livro darwiniano "A origem das espécies" - o qual ultrapassou os limites da ciência e abalou a esfera religiosa já que descartava cientificamente a origem divina pregada pelo Criacionismo- instaurou-se um tempo de mutação. Desta forma, o mundo pensante passou a elaborar novas bases de compreensão do Homem no tempo e no espaço. Esse novo movimento se refletiu no espaço das Artes, Literatura e Filosofia e se potencializou ainda mais com a publicação da Teoria Geral da Relatividade de Einstein, abalando definitivamente o sistema herdado da civilização ocidental progressista cristã. No entanto, ainda há um enigma em torno da compreensão deste novo Homem. "Quem sou eu?" e "Quem é o Outro?" são questões que orientam as produções artísticas, mas que ainda não foram desveladas, continuam sendo um caótico mistério.
\end{abstract}

\begin{abstract}
This article discusses the lines of postmodern thought and its effects on culture as well the place that the new man occupies in this time of transformation. With the publication of Darwin's book "Origin of Species" - which exceeded the limits of science and shook the religious sphere as it denied the divine origin of man, initiated preached by Creationism - initiated a time of change. Thus, the intellectuality has drawn up new bases of understanding of these new man in time and space. This new movement was reflected in the space of Arts, Literature and Philosophy and leveraged further with the publication of the General Theory of Relativity Einstein, shaking definitely the system inherited from the progressive Christian Western civilization. However, there is still a enigma around the understanding of this new man. "Who am I?" and "Who is the Other?" are questions that guide the artistic productions, but which have not yet been answered, remains a mystery chaotic.
\end{abstract}

PALAVRAS-CHAVE: Cultura; Filosofia; ciência naturalista; Literatura

KEYWORDS: Culture; Philosophy; Science Naturalist; Literature 
Uma cultura cyber está em vias de se expandir. [...] Trata-se de uma revolução radical que marca o surgimento da sociedade pós-industrial e implica no nascimento de um novo homem e de um novo pensamento. [...] A cultura cyber é simultaneamente destruição e criação. Se unirá essa cultura com o mito fundador da árvore do conhecimento? (E. Morin)

Cultura não é somente 0 armazenar de conhecimentos, mas a capacidade de interrogar o nosso tempo. (Vergílio Ferreira)

Nas palavras desses grandes espíritos do nosso tempo: o filósofo francês e 0 existencialista português, temos, em síntese, duas das principais linhas de força do pensamento pósmoderno: a da afirmação da natureza complexa/caótica deste nosso tempo-de-mutação (F. Capra) e a da urgência de interrogações, que escavem esse tempo/mundo em que estamos imersos, e possam abrir caminho para uma nova compreensão do lugar que, nele, o Novo Homem (nós, seres humanos) ocupa (ou deve ocupar).

Na verdade, até para os distraídos, já se tornou evidente que, neste limiar do século XXI, estamos vivendo no "olho do furacão", entre um Sistema herdado (o da Civilização Ocidental Progressista/Cristã, cujos valores de base já se deterioraram) e uma nova Cultura em processo (cuja verdadeira natureza ainda é ignorada).

Em meio a esse fenômeno alienador, o importante a notar é que, cada vez com mais força, se vem impondo ao Homem, às Artes, à Literatura, à Filosofia... a questão radical do Ser: "Quem é 0 Homem?", "Quem sou eu?". Interrogações que, fora da esfera da Fé ou da Metafísica, permanecem sem resposta, desde que, na Inglaterra de meados do século XIX, Charles Darwin fez sua entrada no mundo do Conhecimento.

Historicamente, podemos dizer que o nosso tempo-de-mutação teve início com a publicação do livro darwiniano, A Origem das espécies (1859). Verdadeiro arauto das novas descobertas científicas, esse livro (tornado best-seller na época, e consultado até hoje) acabou ultrapassando os limites científicos e atingindo a esfera da Religião. Ao provar a origem do homem "pela seleção natural 
e evolução da matéria", automaticamente o despojava de sua origem divina. A palavra da Ciência, somada ao materialismo da Filosofia Positivista (A. Comte), abala a pedra-base da Civilização Cristã: a verdade bíblica da existência do Deus Criador do Universo e do Homem. Consequentemente, a partir daí, o Mundo Pensante (Ciências/Artes/Literatura/Religiões...) se viu desafiado a descobrir novas bases para a compreensão/explicação do fenômeno Vida/Natureza/Homem/Deus... O homem cristão, tendo perdido sua origem sagrada e alma imortal, se viu reduzido a simples matéria. Para uns, de "alma" o homem virou "lama". Para outros, ao contrário, o homem era descoberto, como "possuidor da Ideia", a grande força criadora, transformadora. (A. Quental). Para o iconoclasta Nietzsche, a transformação seria outra: das ruínas deixadas pela "Morte de Deus", surgiria o Super-Homem e sua Vontade de Poder.

Esse primeiro choque cultural/existencial atingiu em cheio a grande geração literária que surgia na época: Dostoievski, O. Wilde, Yeats, Machado de Assis, Eça de Queirós, Zola, Antero de Quental, Augusto dos Anjos. A obra deixada por cada um deles mostra que cada qual, a seu modo, enfrentou a Nova Esfinge, o Homem sem Deus, mas o fez ainda dentro do universo da Ordem Racional, baseada na Transcendência. Ordem que desde o Renascimento/séc. XVI (início dos Tempos Modernos) consagrara a Razão, como o grande alicerce da Civilização Cristã.

É ainda na Inglaterra (durante o Império da Rainha Vitória) que surge a corrente literária do nonsense antivitoriano, pela voz pioneira de um pacato diácono anglicano e professor de matemática em Oxford, Lewis Carroll. Em 1865, é publicada sua amalucada obra-prima do Absurdo: Alice no país das maravilhas, de imediato sucesso editorial como "literatura fantasista" para divertir crianças. Estava aberto o caminho para o futuro questionamento dos alicerces lógico-racionais da Civilização Tradicional (ainda hoje em discussão). As grandes mutações se dão lentamente no tempo.

Durante a segunda metade do sec. XIX (época em que Alice surgiu), fermentavam e se difundiam as descobertas da Ciência Naturalista (Evolucionismo x Criacionismo), que iriam minar as bases da tradição herdada, a partir da explosão dos "Ismos", que se deu no início do sec. XX. O primeiro grande grito desse homem expulso da antiga ordem racional/divina se dá em Paris no início do século $X X$, na esfera das Artes Plásticas. Anunciada pelo gênio de Picasso, explode a revolução dos Ismos: Cubismo, Dadaísmo, Surrealismo... Pinturas que provocaram escândalo, pois rompiam drasticamente com todas as normas ou técnicas consagradas e criavam, cada qual a seu modo, novos mundos, formas, estilos, impactos... mas todas elas, identificadas entre si, por um denominador comum: a total ausência da Razão ou de uma Lógica ordenadora, que respondesse pelo sentido último das imagens desconexas. Por acaso (?), na época em que Picasso, em Paris, pintava "Les Demoiselles d'Avignon" (1906), dando início à revolução cubista; Einstein, em Berna, acabara de publicar a Teoria Geral da Relatividade (1905), com os primeiros e extraordinários estudos que viriam a revolucionar a Física Clássica, alterando-lhe as bases, e abrindo caminho para um campo de conhecimento inteiramente 
novo, o da "atomização da matéria", objeto da Física Relativista, e demais ramos de pesquisa a ela ligados. À desagregação da imagem-do-mundo seguia-se a desagregação da imagem-do-homem. Era uma página da História que se virava...

Como sempre, as transformações do homem/mundo, que se vão dando ao longo do tempo, encontram sua primeira expressão formal na Imagem. A Palavra nomeadora surge depois... Assim aconteceu com a "gestação" do Pós-Moderno: após a explosão da Imagem, surge a explosão da Palavra, denunciando o caos... Ainda em Paris, em 1922, quando já baixara a efervescência dos Ismos, é publicado em língua inglesa o genial/caudaloso/desordenado romance que, apesar do escândalo provocado na época, se transformaria num marco da Pós-Modernidade: o desafiante Ulisses, de James Joyce.

A partir daí, estava aberto o caminho para o novo Ulisses dos Tempos Pós-Modernos: aquele que viaja dentro de si mesmo em busca de seu próprio ser. O homo sapiens, herdeiro de milênios de Conhecimento, inventor/construtor deste mágico mundo cibernético, no qual ele se vê perdido espécie de "aprendiz de feiticeiro", homem-joguete das mil formas da Nova Cultura, que ele próprio engendrou: dos "labirintos borgianos" à "cultura mosaico" (Jean Onimus), ou "cultura cyber" (Morin), ou "Ponto-de-mutação" (Capra), "Contracultura", ou... ou... Um Ulisses, cuja "viagem" há muito foi mercantilizada e transformada em "turismo", mas que, nos "pensantes", permanece como um perambular contínuo pelos labirintos do mundo interior.

As Artes, a Literatura, a Poesia, o Teatro... multiplicam-se em criações experimentais, que têm a identificá-las (como expressão de um determinado momento histórico/cultural) um só dado comum: a fragmentação, que desafia o homem interrogante do nosso tempo.

O filósofo Thomas Hanna (Corpos em Revolta, 1976) vai mais longe: sua visionária "cultura somática" (que engloba Darwin, Freud, Jung, Nietzsche, Kant, Marx...) analisa a "rebelião cultural", que já estaria se processando nos "corpos humanos", nas "mentes aceleradas", nos "corpos em revolta", que se agitam/atuam no novo ambiente. Aquele que vem sendo criado/ construído pela Inteligência dos homens e que, ao se realizar e expandir em plenitude, como neste nosso tempo, está transformando o próprio homem (que o criou e nele habita) no "mutante cultural", - criador de uma "nova cultura" que se revolta contra a cultura herdada. Nietzsche já antevira o surgimento do Super-Homem... Jung descobre que é o próprio Homem, em sua ação transformadora sobre o mundo, que através das Eras, vai reelaborando as matrizes arcaicas do Inconsciente Coletivo (espaço de "imagens arquetípicas", que modelam o Ego e, sobre as quais, este por sua vez, com o tempo, acaba por atuar, reelaborando-as...). Processo esse que se perpetua no tempo...

Ainda nessa ordem de ideias, alguns "visionários" que habitam 0 mundo das Artes, da Poesia, da Cultura... "profetizam" que estamos vivendo no limiar de uma Nova Era, cuja natureza está ainda encoberta, ainda é enigma, mas já deixa entrever que o seu novo centro, seu novo eixo-geratriz 
é o Homem, esse desconhecido. Enigma que Fernando Pessoa, há mais de um século, procurou desvendar: "De quem é o olhar / que espreita por meus olhos?/ Quando penso que vejo, / Quem continua vendo / Enquanto estou pensando?" Interrogações, para as quais, o grego Kazantsaki deveria entrever alguma resposta, ao escrever em sua Carta a Greco (1956): "Não é o homem que precisa de Deus, mas Deus que precisa do homem." Negado pela Ciência, Deus precisa ser renomeado pelo Homem. Como?

É esse o momento em que vivemos. No vazio deixado pela Palavra de Deus, faz-se ouvir a palavra do homem que pergunta por si mesmo: "Quem é o Homem?" "Quem sou eu?" "Quem é o outro?" Sem dúvida, é essa a questão radical que energiza toda a criação artística/literária/poética/teatral.... nestes "tempos de cólera"... É também o eixo-motriz da filosofia existencial e leva Heidegger a concluir: "Nunca se conheceram tantas e tão diversas coisas sobre o homem, como em nosso tempo. [...] Entretanto, em época nenhuma, se soube menos sobre o que o homem é. Em tempo algum, 0 homem foi tão problemático como no atual." Heidegger teria razão absoluta ao considerar o nosso tempo como exceção? Lembramos, por acaso, que Sófocles, em Antígona (séc. V a. C.), exclamava: "Muitos são os grandes enigmas que povoam a terra, porém nada mais enigmático que o homem" (SÓFOCLES: 1970). E à Grécia, não faltavam deuses...

Talvez não seja absurdo afirmar que, desde que o homem se descobriu como "ser-no-mundo", ele anda em busca de si mesmo... e de um "deus" que o justifique...

E la nave vá... 


\section{Referências}

CARROLL, Lewis. Alice no País das Maravilhas. tradução: Nicolau Sevcenko. São Paulo: Scipione, 1992.

DARWIN, Charles. A Origem das espécies. tradução: Eduardo Fonseca. São Paulo: Hemus, 19821.

EINSTEIN, A. Teoria da Relatividade Especial e Geral. tradução: Carlos Almeida Pereira. Rio de Janeiro, 1999.

HANNA, Thomas. Corpos em revolta: uma abertura para o pensamento somático. Rio de Janeiro: Mundo Musical 1976.

PESSOA, Fernando. Obra Poética. Rio de Janeiro: Nova Aguilar, 2003.

SÓFOCLES. Antígona. tradução: Mário da Gama Kuryófocles. Rio de Janeiro: Civilização Brasileira, 1970. 